\title{
Epidemiological Aspects and Clinicopathological Findings in Cats Naturally Infected with Feline Leukemia Virus (FeLV) and/or Feline Immunodeficiency Virus (FIV)
}

\author{
Victorio M. Collado ${ }^{1}$, Ana Domenech ${ }^{1}$, Guadalupe Miró ${ }^{1}$, Sonsoles Martin², Elena Escolar ${ }^{2}$, \\ Esperanza Gomez-Lucia ${ }^{*}$ \\ ${ }^{1}$ Departamento Sanidad Animal Facultad de Veterinaria, Universidad Complutense, Madrid, Spain \\ ${ }^{2}$ Departamento Medicina y Cirugía Animal, Facultad de Veterinaria, Universidad Complutense, Madrid, Spain \\ Email:"duato@vet.ucm.es
}

Received January 29, 2012; revised February 14, 2012; accepted February 24, 2012

\begin{abstract}
Infections produced by feline immunodeficiency virus (FIV) and feline leukemia virus (FeLV), two of the most prevalent pathogens in cats, range from passing unnoticed to presenting a wide variety of clinical signs. Different epidemiological, clinical, hematological and virological parameters were analyzed in 78 FIV- and/or FeLV-infected cats. FeLV-infected $\left(\mathrm{FeLV}^{+}\right)$cats were considerably younger than $\mathrm{FIV}$-infected $\left(\mathrm{FIV}^{+}\right)$cats, and in general were seen to have a more severe disease than $\mathrm{FIV}^{+}$cats. Around one third of the cats presented anemia, and neutropenia was also frequently observed. Though a higher percentage of $\mathrm{FIV}^{+}$than $\mathrm{FeLV}^{+}$cats had altered leukocyte counts, $\mathrm{FeLV}^{+}$cats had altered counts of both neutrophils and lymphocytes more frequently than $\mathrm{FIV}^{+}$, which usually presented only either altered neutrophils or lymphocyte counts. Virological markers were only detected in FeLV ${ }^{+}$cats, either as mono- or dual-infection, and correlated with the severity of the disease, but not in $\mathrm{FIV}^{+}$cats. In conclusion, these results suggest that FeLV affects more blood cell types and provokes death of affected animals at a much earlier age than FIV and that the severity of the disease seemed to depend on the viral status of the cat.
\end{abstract}

Keywords: FIV; FeLV; Epidemiology; Hemogram; CD4:CD8 Ratio

\section{Introduction}

Feline immunodeficiency virus (FIV) and feline leukemia virus (FeLV) are two of the most prevalent causes of feline infections worldwide [1]. FeLV, a gammaretrovirus, has a simple genome consisting only of the genes necessary for replication and particle formation ( $g a g, p o l$ and $e n v)$. For this reason, it can only replicate in actively dividing cells, such as those in the bone marrow or lining the small intestine [2]. FIV is a lentivirus, proposed as the best animal model for the study of human immunodeficiency virus (HIV). As such, its genome, besides the above mentioned genes, encodes other accessory proteins that enable the virus to regulate the replication cycle more efficiently, thus productively infecting non-dividing cells [2]. If FeLV is not cleared early from the body by an initial strong immune response, it produces a persistent infection. Characteristically, the virus remains latent in cells of the bone marrow, but eventually animals die as a result of it. On the contrary, when FIV is inoculated into a bitten cat it replicates in monocytes, macrophages and lymphocytes, and

${ }^{*}$ Corresponding author. spreads throughout the body. The decrease in lymphocytes and macrophages targeted by FIV induces a progressive breakdown of the immune system, which may lead to death [2-4].

In general terms, both infections produce similar clinical signs and it is difficult to establish a precise clinical diagnosis [5]. This is further confused by the possibility of animals infected by both viruses (double infected), as they both may induce a state of immunosuppression which weakens immunological defenses. FeLV-infection can cause hematologic disorders directly or indirectly, and other clinical signs such as FeLV enteritis, gingivostomatitis, immunosuppression, abortion and infertility $[2,6,7]$. Clinical signs associated with FIV-infection are immunosuppression, chronic persistent infections, B-cell lymphomas, leukemia, digestive disorders, neurologic disorders and anemia $[2,4]$. In addition to all this, cats may be markedly sick by most biopathological parameters, but look clinically healthy.

Cats naturally infected represent a non-replaceable system to analyze the alterations produced by retroviruses in field conditions, which are those encountered by prac- 
titioners. The aim of the present work was to determine whether the alteration of the hematological parameters, relatively easy to evaluate, could be associated to the comparatively more difficult to measure virological parameters (such as increased viral proteins or reverse transcriptase activity) and correlated with the severity of the disease (as judged by the clinical status of the cat) in cats infected naturally by FeLV and/or FIV in Spain. This study formed part of a larger study on the efficacy of type I interferon for treating feline retrovirosis.

\section{Materials and Methods}

\subsection{Animals}

Seventy-eight cats infected with FIV $\left(\mathrm{FIV}^{+}\right)$, FeLV $\left(\mathrm{FeLV}^{+}\right)$or both $\left(\mathrm{FF}^{+}\right)$, either privately owned or living in cat shelters, were included in the study, which spanned from 2005 to 2007 . They were attended by the veterinarians in any of the participating private veterinary practices located in different parts of Spain, or in the Infectious and Parasitic Diseases Unit of the Veterinary Clinic Hospital (VCH) of the Complutense University in Madrid. They had all tested positive to either or both viruses by the serologic Snap Combo Plus (Idexx Laboratories Inc., Westbrook, ME, USA), which detects FeLV p27 and antibodies simultaneously against FIV Gag and Env proteins. The length of time between the acquisition of retroviral infection and diagnosis was unknown in all cats. No pregnant queens, cats difficult to manage or with neoplasia, in the final stages of the disease (complete lack of appetite and prostration and generalized lymphadenopathy) or with other concomitant severe diseases, or treated with immunomodulators (corticoesteroids, etc.) were included. Owners were informed about the study and signed a written consent to be included in the study. The age, breed, sex, neutering status, and the clinical signs were recorded.

\subsection{Clinical Evaluation}

The clinical signs most frequently observed in feline retrovirosis reported in literature and according to the experience of the participating practitioners were rated according to their relevance in the disease (Table 1) and evaluated in cats to obtain a clinical score (CS). According to this CS, cats were classified into three clinical groups (CG): CG1, with no clinical signs (asymptomatic); $\mathrm{CG} 2$, with $\mathrm{CS} \leq 5$ (mild disease); and CG3, with $\mathrm{CS} \geq 6$ (severe disease).

\subsection{Blood Sampling and Processing}

Blood samples $(2 \mathrm{ml})$ were collected from the cephalic or jugular veins. Stressed cats were tranquilized with medetomidine (Domtor ${ }^{\circledR}$, Pfizer Salud Animal SA, Madrid, Spain), to avoid the development of stress leuko-
Table 1. Score assigned to each of the most frequent clinical signs associated with feline retroviral infection, considering their relative value within the disease range $(0$, absence; 1 , mild; 2, severe).

\begin{tabular}{|c|c|c|c|}
\hline \multirow{2}{*}{ Clinical signs } & \multicolumn{3}{|c|}{ Score } \\
\hline & $\mathbf{0}$ & 1 & 2 \\
\hline Loss of appetite & No & Partial (disorexia) & Total (anorexia) \\
\hline Asthenia & No & Slight depression & Severe-prostration \\
\hline Dehydration & No & $<10 \%$ & $>10 \%$ \\
\hline Weight loss & No & Thinness & Cachexia \\
\hline Lymphadenomegaly & No & Localized & Generalized \\
\hline Altered mucosae & No & Pale-congestive & \\
\hline Polyuria/polydipsia & No & Yes & \\
\hline Conjunctivitis & No & & Yes \\
\hline Keratitis & No & & Yes \\
\hline Oral lesions & No & & Yes \\
\hline Digestive disorders & No & Yes & \\
\hline Cutaneous lesions & No & Pruritus, alopecia & Nodules, ulcers \\
\hline $\begin{array}{l}\text { Respiratory } \\
\text { disorders }\end{array}$ & No & Mild & Severe \\
\hline $\begin{array}{l}\text { Neurologic } \\
\text { disorders }\end{array}$ & No & & Yes \\
\hline Lymphoma & No & & Yes \\
\hline $\begin{array}{l}\text { Myeloproliferative } \\
\text { disorders }\end{array}$ & No & & Yes \\
\hline \multirow[t]{2}{*}{ Other neoplasia } & No & & Yes \\
\hline & \multicolumn{3}{|c|}{ Maximal score $=31$} \\
\hline
\end{tabular}

gram. Blood was distributed into a tube with EDTA and another with Heparin-Lithium and sent within 24 hours after collection at $4^{\circ} \mathrm{C}$ to the Dept. of Animal Health.

\subsection{Biopathological Analyses}

The hemogram was determined automatically (Sysmex F-800 Microcellcounter, Sysmex Corp., Kobe, Japan) from EDTA anticoagulated blood. Differential leukocyte counts were determined manually in the Biopathology Laboratory of the VCH from May-Grumwald Giemsa stained blood smears, and morphological abnormalities were recorded. The reference values used for normality in the Laboratory were: packed cell volume (PCV), 26\% - 45\%; red blood cells count (RBC), $5-10 \times 10^{6}$ cells $/ \mu 1$; hemoglobin concentration (Hgb), 8 - $15 \mathrm{~g} / \mathrm{dl}$; mean corpuscular volume, 39 - $55 \mathrm{fl}$; mean corpuscular hemoglobin, 12.5 - $17.5 \mathrm{pg} / \mathrm{cell}$; mean corpuscular hemoglobin concentration, $30-36 \mathrm{~g} / \mathrm{dl}$; white blood cells count (WBC), $5.5-19.5 \times 10^{3}$ cells $/ \mu \mathrm{l}$; segmented neutrophil 
count (Ntr), 2500 - 12,500 cells/ $\mu 1$; lymphocytes (Lym) 1500 - 7700 cells $/ \mu \mathrm{l}$; monocytes, 0 - 850 cells $/ \mu \mathrm{l}$; eosinophils, 0 - 1500 cells $/ \mu 1$; basophils, 5.5 - 19.5 cells $/ \mu 1$. Relative abnormalities were rated as $\mathrm{L}$ or $\mathrm{H}$, when they were below or above, respectively, the reference values. In the case of PCV, L (20\% - 26\%), LL (14\% - 20\%), and LLL $(<14 \%)$ were considered.

\subsection{Determination of the $\mathrm{CD}^{+}{ }^{+} \mathrm{CD8}^{+}$Ratio by Flow Cytometry}

The $\mathrm{CD}^{+} \mathrm{CD}^{+}$ratio was determined in the EDTA anticoagulated blood after lysing RBCs (BD FACS Lysing Solution, Becton Dickinson Biosciences, San Diego, CA, USA) for $3 \mathrm{~min}$. Monoclonal antibodies against feline CD4 and CD8 labeled with fluorescein and rodamin (Southern Biotechnology Associates Inc., Birmingham, AL, USA), respectively, were added ( $2 \mu \mathrm{l}$ of each) to one tube, using another one as a blank. Samples were analyzed in a flow cytometer (Becton Dickinson FAC-Scan, Becton Dickinson Biosciences) in the Centre Luis Bru of the Complutense University of Madrid. The ratio was considered decreased when it was $<0.9$.

\subsection{Detection of FeLV p27, FIV p24 and Retrotranscriptase Activity (RT)}

The concentration of FeLV p27 and FIV p24 was determined in the plasma of the cats diluted 1:2 in PBS, using the commercial tests PetChek FeLV Antigen Test and PetChek FIV Antigen Test (Idexx), respectively, and the RT activity of FeLV and FIV using the C-type-RT ${ }^{\mathrm{TM}}$ Activity Assay, and Lenti-RT ${ }^{\mathrm{TM}}$ Activity Assay (Cavidi Tech, Uppsala, Sweden), respectively. Appropriate negative controls and the positive controls included in the kits were used. Color development was measured in a spectrophotometer (Tecan Spectra-Fluor A-5082, Crailsheim, Germany), and data were interpreted following the manufacturers' directions.

\subsection{DNA Extraction and Polymerase Chain Reaction (PCR)}

DNA was extracted from the heparinised blood using the
DNeasy Tissue Kit (Qiagen, Chatsworth, CA, USA). The presence of the provirus in peripheral blood was determined using the nested PCR technique designed in our laboratory [8]. Reagents were purchased from Biotools (Madrid, Spain), with the exception of the primers (Genosys-Sigma).

\subsection{Statistical Analysis}

The results obtained were analyzed in the Data Processing Center of the Complutense University. Multiple variable analyses were done. Results were compared using cross-tabulation, contingency coefficient, Fishers exact test, Chi-square and T-Student, with a significance of 0.95 . Correlations were done using the program SAS, and they were considered statistically significant when $p$ $<0.05$. Correlations $\geq 0.7$ were considered high and when they were $0.4-0.7$ moderate. All data were cross-tabulated. Only significant differences are mentioned in the text.

\section{Results}

\subsection{Epidemiology of FeLV and FIV Infections}

Of the 78 cats included in the study, 38 (48.7\%) were infected with FIV $\left(\mathrm{FIV}^{+}\right), 31(39.7 \%)$ with FeLV $\left(\mathrm{FeLV}^{+}\right)$, and $9(11.5 \%)$ were infected with both viruses $\left(\mathrm{FF}^{+}\right)$. Sex and neutered status of the study cats are shown in Table 2. There was a statistically significant difference $(\mathrm{p}<0.05)$ between the age distribution in both types of infection (Figure 1). The mean ages were 1.9 years, 3.6 years and 4.9 years for $\mathrm{FeLV}^{+}$(excluding a cat that was 10 years old), $\mathrm{FF}^{+}$and $\mathrm{FIV}^{+}$cats, respectively.

\subsection{Clinical Status}

The clinical situation of the cats included in the study was quite heterogeneous (Table 3). Cats were classified into three groups according to their clinical scoring as described in Materials and Methods. Of the FeLV ${ }^{+}$cats, 11 $(35.5 \%)$ did not show any clinical sign (CG1), while in 9 $(29 \%)$ the CS was $\leq 5$ (CG2), and in $11(35.5 \%)$ it was $\geq 6$ (CG3). In $\mathrm{FIV}^{+}$cats, the percentages were $31.6 \%$, 36.8\%,

Table 2. Sex distribution of the cats included in the study.

\begin{tabular}{|c|c|c|c|c|c|c|c|c|c|}
\hline \multirow{2}{*}{ Sex } & \multirow{2}{*}{ Neutered } & \multicolumn{2}{|c|}{$\mathrm{FeLV}^{+}(\mathrm{n}=31)$} & \multicolumn{2}{|c|}{$\mathrm{FIV}^{+}(\mathrm{n}=38)$} & \multicolumn{2}{|c|}{$\mathrm{FF}^{+}(\mathrm{n}=9)$} & \multicolumn{2}{|c|}{ Total $(\mathrm{n}=78)$} \\
\hline & & Total & & Total & & Total & & Total & \\
\hline \multirow{2}{*}{ q } & no & \multirow{2}{*}{$18(58.1)$} & $7(22.6)^{*}$ & \multirow{2}{*}{$13(34.2)$} & $4(10.5)$ & \multirow{2}{*}{$2(22.2)$} & $1(11.1)$ & \multirow{2}{*}{$33(42.3)$} & $12(15.4)$ \\
\hline & yes & & $11(35.5)$ & & $9(23.7)$ & & $1(11.1)$ & & $21(26.9)$ \\
\hline \multirow[b]{2}{*}{0} & no & \multirow[b]{2}{*}{$13(41.9)$} & 4 (12.9) & \multirow[b]{2}{*}{$25(65.8)$} & $8(21.0)$ & \multirow[b]{2}{*}{$7(77.8)$} & $1(11.1)$ & \multirow[b]{2}{*}{$45(57.7)$} & $13(16.7)$ \\
\hline & yes & & $9(29.0)$ & & $17(44.7)$ & & $6(66.7)$ & & $32(41.0)$ \\
\hline
\end{tabular}

*Percentages are shown in braquets. 


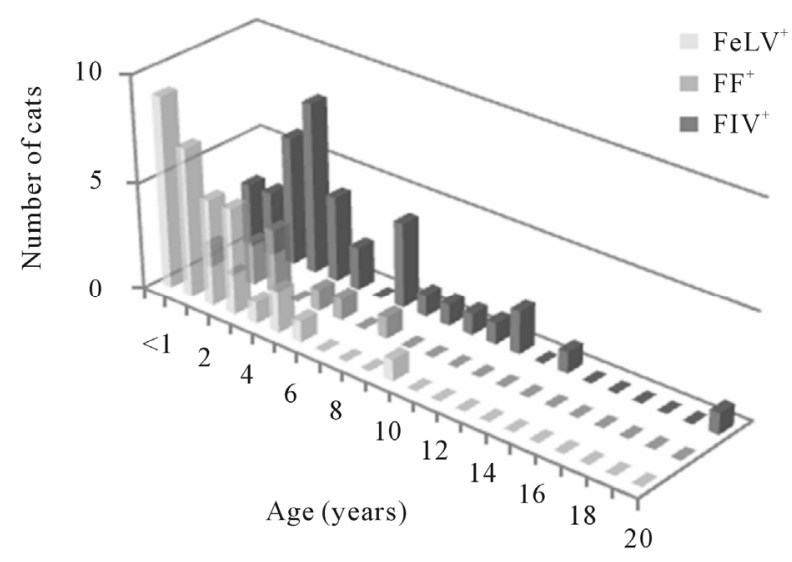

Figure 1. Age distribution of the cats included in the study.

Table 3. Percentage of $\mathrm{FeLV}^{+}, \mathrm{FF}^{+}$and $\mathrm{FIV}^{+}$cats presenting the different clinical signs. Range of score, average clinical score (CS) for all the cats in the group, and average CS for all cats in the group presenting clinical signs.

\begin{tabular}{|c|c|c|c|c|}
\hline Clinical sign & $\begin{array}{l}\text { FeLV }^{+} \\
\mathbf{n}=31\end{array}$ & $\begin{array}{c}\mathbf{F I V}^{+} \\
\mathbf{n}=\mathbf{3 8}\end{array}$ & $\begin{array}{c}\mathbf{F F}^{+} \\
\mathbf{n}=\mathbf{9}\end{array}$ & $\begin{array}{r}\text { Total } \\
\mathrm{n}=78\end{array}$ \\
\hline Loss of appetite & $40.7 \%$ & $64.5 \%$ & $88.9 \%$ & $50.0 \%$ \\
\hline Asthenia postration & $44.4 \%$ & $45.2 \%$ & $66.7 \%$ & $41.0 \%$ \\
\hline Altered mucosae & $40.7 \%$ & $35.5 \%$ & $55.6 \%$ & $34.6 \%$ \\
\hline Oral lesions & $40.7 \%$ & $41.9 \%$ & $11.1 \%$ & $32.0 \%$ \\
\hline Respiratory disorders & $37.0 \%$ & $29.0 \%$ & $11.1 \%$ & $25.6 \%$ \\
\hline Lymphadenomegaly & $29.6 \%$ & $19.4 \%$ & $44.4 \%$ & $23.1 \%$ \\
\hline Cutaneous lesions & $22.2 \%$ & $19.4 \%$ & $33.3 \%$ & $19.2 \%$ \\
\hline Weight loss & $18.5 \%$ & $29.0 \%$ & 0 & $17.9 \%$ \\
\hline Digestive disorders & $18.5 \%$ & $16.1 \%$ & $44.4 \%$ & $17.9 \%$ \\
\hline Conjunctivitis & $29.6 \%$ & $16.1 \%$ & 0 & $16.7 \%$ \\
\hline Polyuria/polydipsia & 0 & $6.5 \%$ & $33.3 \%$ & $6.4 \%$ \\
\hline Dehydration & $3.7 \%$ & $6.5 \%$ & 0 & $3.8 \%$ \\
\hline Neurologic disorders & $3.7 \%$ & $3.2 \%$ & 0 & $2.6 \%$ \\
\hline Keratitis & 0 & $3.2 \%$ & 0 & $1.3 \%$ \\
\hline Range of CS & $0-13$ & $0-9$ & $3-6$ & \\
\hline $\begin{array}{l}\text { Average of clinical score } \\
\text { for cats of the group }\end{array}$ & 3.97 & 3.39 & 4.56 & \\
\hline $\begin{array}{l}\text { Average of clinical score } \\
\text { for cats presenting } \\
\text { clinical signs }\end{array}$ & 6.15 & 5.0 & 4.56 & \\
\hline
\end{tabular}

and $31.6 \%$ for $\mathrm{CG} 1, \mathrm{CG} 2$, and $\mathrm{CG} 3$, respectively.

All the double infected cats $\left(\mathrm{FF}^{+}\right)$had signs $(66.7 \%$ were in CG2, and $33.3 \%$ in CG3). The clinical status of the $\mathrm{FeLV}^{+}$cats showing illness was worse than the $\mathrm{FIV}^{+}$ group, as the average clinical scoring, especially of the animals showing clinical signs, was higher in the former than in the latter (Table 3).

A statistically significant difference was detected when analyzing the age distribution of the $\mathrm{FeLV}^{+}$cats according to their clinical score. Of the $\mathrm{FeLV}^{+}$cats, $72.7 \%$ of those included in CG3 were $<1$ year old, a higher percentage than in CG2 (22.2\%) or CG1 (18.2\%) $(\mathrm{p}<0.05)$ (Figure 2 ). In the group of $\mathrm{FIV}^{+}$cats, the severity of the disease seemed to increase with age, as $56.5 \%$ and $75.0 \%$ of cats 1 7 years old and $\geq 7$ years old, respectively, showed clinical signs (Figure 2).

For both infections, most male cats showed clinical signs $\left(84.6 \%\right.$ and $72.0 \%$ for $\mathrm{FeLV}^{+}$and $\mathrm{FIV}^{+}$males, respectively), while less females did $(50.0 \%$ and $61.5 \%$ for $\mathrm{FeLV}^{+}$and $\mathrm{FIV}^{+}$females, respectively). In the infection by FeLV, this difference in sex was statistically significant $(p<0.05)$, and the average clinical score was higher for males (4.4) than for females (3.7), which was contrary to the situation in $\mathrm{FIV}^{+}$cats, where the disease was more severe in females than in males (CS 3.7 and 3.2, respectively).

\subsection{Laboratory Findings}

The analysis of the hemogram is very important, since it is the parameter altered most frequently in both infections. Three of the erythrogram parameters studied, PCV, Hgb, and $\mathrm{RBC}$, were found to be altered in several infected cats
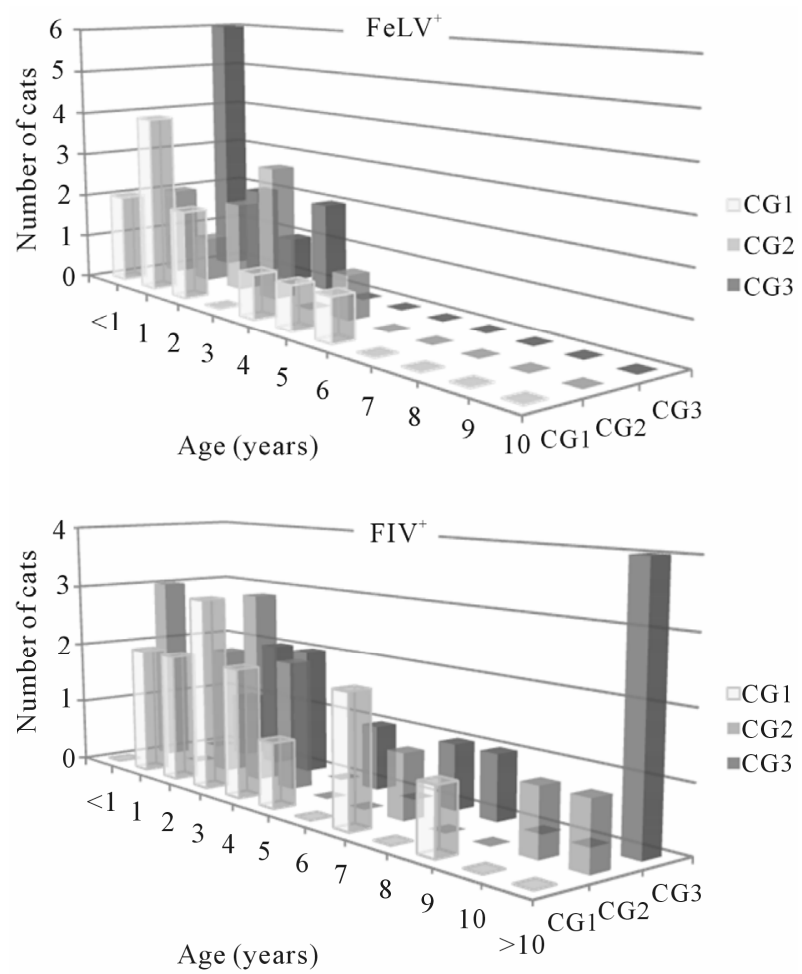

Figure 2. Distribution in clinical groups (CG) of the cats included in the study according to age. 
(Table 4). Ten $\mathrm{FeLV}^{+}$cats $(32.3 \%), 5 \mathrm{FF}^{+}$cats $(55.6 \%)$, and $12 \mathrm{FIV}^{+}$cats $(31.6 \%)$ had non-regenerative anemia, which was mild (PCV 20\% - 26\%) in all but two cats (one $\mathrm{FIV}^{+}$and one $\mathrm{FeLV}^{+}$4-month-old kittens, which had all the red blood series parameters altered, and lymphopenia). In FeLV infection, cats with clinical signs (CG2 and 3) had a higher trend to have anemia than those without (30.0\% and $9.1 \%$, respectively).

Abnormalities in the absolute neutrophil and/or lymphocyte counts were detected in $45.2 \%$ of the $\mathrm{FeLV}^{+}$, $55.3 \%$ of the $\mathrm{FIV}^{+}$, and $44.4 \%$ of the $\mathrm{FF}^{+}$cats, when compared to the reference ranges used in the laboratory. In general, in both infections there was a higher percentage of cytopenias than cytophilias, and neutropenia was the most frequent alteration $\left(35.5 \%\right.$ of $\mathrm{FeLV}^{+}, 31.6 \%$ of $\mathrm{FIV}^{+}$, and $22.2 \%$ of $\mathrm{FF}^{+}$cats). Neutrophilia was observed in $15.8 \% \mathrm{FIV}^{+}$and in $22.2 \% \mathrm{FF}^{+}$cats, mostly in cats with clinical signs.

Though a higher percentage of $\mathrm{FIV}^{+}$than $\mathrm{FeLV}^{+}$cats had abnormal WBC counts, more leukocyte populations were affected in $\mathrm{FeLV}^{+}$cats than in $\mathrm{FIV}^{+}$cats, as $40.0 \%$ of the $\mathrm{FeLV}^{+}$cats with altered WBC counts had both the neutrophil and lymphocyte counts altered, versus $18.2 \%$ of the $\mathrm{FIV}^{+}$cats, and $20.0 \%$ of the $\mathrm{FF}^{+}$cats.

The $\mathrm{CD}^{+}: \mathrm{CD}^{+}$ratio could not be analyzed in 12 cats due to the poor quality of the sample. It was decreased $(<0.9)$ in $29.6 \%$ of $\mathrm{FeLV}^{+}$cats (Table 4$)$, with the average ratio being 1.66. The percentage of $\mathrm{FIV}^{+}$cats in which the ratio was altered was significantly higher than in $\mathrm{FeLV}^{+}$ $(65.6 \% ; p<0.01)$, with an average ratio of 0.80 , which was a similar ratio to $\mathrm{FF}^{+}$cats. Though the differences were not statistically significant, the average of $\mathrm{CD}^{+}$: $\mathrm{CD}^{+}$ratio in $\mathrm{FeLV}^{+}$cats included in $\mathrm{CG} 3$ (1.22) was lower than those in CG2 (1.69) or in CG1 (1.91). Similarly, the average $\mathrm{CD}^{+}: \mathrm{CD}^{+}$in $\mathrm{FIV}^{+}$cats was $0.92,0.76$ and 0.75 for CG1, CG2 and CG3, respectively.

\subsection{Viral Parameters}

All $\mathrm{FeLV}^{+}$and $\mathrm{FF}^{+}$cats included in the study were positive to the FeLV p27CA antigen (criterion of inclusion); however, FIV p24CA could not be detected in any of the cats. Infective viral particles were evaluated indirectly through the calculation of the RT activity in the plasma of all cats. No sample was positive to Lenti-RT ${ }^{\mathrm{TM}}$ described in Materials and Methods. Statistically significant differences $(\mathrm{p}<0.05)$ were found between the clinical groups in $\mathrm{FeLV}^{+}$cats, as $45.5 \%$ of CG1, $66.7 \%$ of CG2 and $100 \%$ of CG3 had detectable levels of RT activity (Table 4). In addition, a higher percentage of male $\mathrm{FeLV}^{+}$ cats $(90.0 \%)$ than female $(61.1 \%)$ had detectable RT levels.

The pol sequence was amplified in the DNA of all cats included in the study by nested PCR. In FeLV ${ }^{+}$cats, this parameter had a significantly positive correlation $(\mathrm{p}<$ $0.05)$ with the concentration of $\mathrm{p} 27 \mathrm{CA}(\mathrm{R}=0.47)$ and $\mathrm{RT}$ activity $(\mathrm{R}=0.41)$ and negative with the $\mathrm{CD} 4^{+}: \mathrm{CD}^{+}$ratio $(\mathrm{R}=-0.42)$. No correlation was observed between the RT activity and the WBC counts.

\section{Discussion}

Results of the present study corroborate previous observations in several aspects. Nonetheless, while other studies focus on any of the four aspects included in this study (epidemiology, clinical, hematological and virological findings), few compare all of them. In view of our results, none of the parameters analyzed may be used solely as a marker of the severity of the disease.

Sex distribution results agreed with the characteristic epidemiology of both infections and with data from pre-

Table 4. Number and percentage (shown in braquets) of cats in each clinical group showing hematological alterations and/or detection of RT.

\begin{tabular}{|c|c|c|c|c|c|c|c|c|c|c|}
\hline \multirow{2}{*}{ Category } & \multirow{2}{*}{ Parameter } & \multicolumn{3}{|c|}{$\mathrm{FeLV}^{+}$} & \multicolumn{3}{|c|}{$\mathrm{FF}^{+}$} & \multicolumn{3}{|c|}{$\mathrm{FIV}^{+}$} \\
\hline & & $\begin{array}{c}\text { CG1 } \\
\mathrm{N}=11\end{array}$ & $\begin{array}{l}\mathrm{CG} 2 \\
\mathrm{~N}=9\end{array}$ & $\begin{array}{c}\text { CG3 } \\
\mathrm{N}=11\end{array}$ & $\begin{array}{c}\text { CG1 } \\
\mathrm{N}=0\end{array}$ & $\begin{array}{c}\mathrm{CG} 2 \\
\mathrm{~N}=6\end{array}$ & $\begin{array}{c}\text { CG3 } \\
\mathrm{N}=3\end{array}$ & $\begin{array}{c}\text { CG1 } \\
\mathrm{N}=12\end{array}$ & $\begin{array}{c}\mathrm{CG} 2 \\
\mathrm{~N}=14\end{array}$ & $\begin{array}{c}\text { CG3 } \\
\mathrm{N}=12\end{array}$ \\
\hline \multirow{3}{*}{ Erythrogram } & $\downarrow \mathrm{PCV}$ & $4(36.4)$ & $3(33.3)$ & $3(27.3)$ & & $4(66.7)$ & $1(33.3)$ & $3(25.0)$ & $4(28.6)$ & $4(33.3)$ \\
\hline & $\downarrow \mathrm{Hgb}$ & $3(27.3)$ & $3(33.3)$ & $3(27.3)$ & & $3(50.0)$ & $1(33.3)$ & $2(16.7)$ & $4(28.6)$ & $4(33.3)$ \\
\hline & $\downarrow R B C$ & $1(9.1)$ & $3(33.3)$ & $3(27.3)$ & & $3(50.0)$ & 0 & $1(8.3)$ & $3(21.4)$ & $3(25.0)$ \\
\hline \multirow{3}{*}{ Leukogram } & $\mathrm{WBC}^{\mathrm{a}}$ & $4(36.4)$ & $1(11.1)$ & $3(27.3)$ & & $1(16.7)$ & $1(33.3)$ & $4(33.3)$ & $3(21.4)$ & $5(41.7)$ \\
\hline & $\mathrm{Ntr}^{\mathrm{a}}$ & $5(45.5)$ & $1(11.1)$ & $5(45.5)$ & & $4(66.7)$ & 0 & $5(41.7)$ & $6(42.9)$ & $7(58.3)$ \\
\hline & $\operatorname{Lym}^{\mathrm{a}}$ & $4(36.4)$ & $1(11.1)$ & $4(36.4)$ & & $1(16.7)$ & 0 & $2(16.7)$ & $2(14.3)$ & $3(25.0)$ \\
\hline \multirow{2}{*}{ Other } & $\downarrow \mathrm{CD} 4: \mathrm{CD} 8^{\mathrm{b}}$ & $2 / 10$ & $1 / 8$ & $5 / 9$ & & $4 / 5$ & $2 / 2$ & $5 / 11$ & $10 / 12$ & $6 / 9$ \\
\hline & $\mathrm{RT}^{* *}$ & $5(45.5)$ & $6(66.7)$ & $11(100)$ & & $4(66.7)$ & $2(66.7)$ & & & \\
\hline
\end{tabular}

${ }^{\mathrm{a}}$ Includes both increased and decreased values; ${ }^{\mathrm{b}}$ The number of animals in the group in which the $\mathrm{CD} 4^{+}: \mathrm{CD} 8^{+}$ratio could be determined is shown; ${ }^{\mathrm{c}}$ Type-C RT (FeLV); $\downarrow$ Decreased value; $\uparrow$ Increased value. 
vious studies [2,4,6-9]. In FeLV infection, the disease was more severe in males than in females, as a higher percentage of males than females presented clinical signs, and the mean clinical score was 4.4 and 3.7, respectively. In addition, a higher percentage of males than females had detectable concentration of RT activity, which is a measure of infective viral particles.

The 14 clinical signs reported as most frequent for these retrovirosis were examined. The clinical values for the scoring were established depending on their relative importance in both retroviral infections reported in the literature, and according to the experience of the practitioners participating in the study. As described previously [2, $4,7,10,11]$, the clinical picture varied considerably, as corresponds to the non-specificity of the clinical signs for both infections. Infected cats were classified into three clinical groups according to their clinical scoring. CG1 included animals with no clinical signs. However, most of these cats had at least one of the analyzed hematological parameters altered. This group would include cats in the clinical latency stage of the disease in which the virus replicates without clinical signs of the infection, but affects the analyzed parameters. CG2 and CG3 contain cats with active disease, which would need a follow-up exam to determine whether they are in the initial stages, in a relapse or in the final stages of the disease. Cats in CG2, with few clinical signs (clinical score $\leq 5$ ), were considered to have mild disease, and in CG3, with a variety of clinical signs, to have severe disease. The average of CS for cats presenting clinical signs was lower in the $\mathrm{FF}^{+}$cats than in the other two groups, which would mean that both viruses do not synergize to produce a more severe form of the disease, in disagreement with previous reports [12].

A strong dependency of the infection on the age was also detected. The mean age for FeLV-infection was 1.9 years, and all except one cat were $<7$ years old. Cats less than 1 year old had a more severe form of the disease than adult cats, as $60.0 \%$ of the former had a CS $\geq 6$ (CG3), while only $23.8 \%$ of adults did. These results agree with data from other authors [8,13-15], and suggest that FeLV infects cats early in their life, it is aggressive, and the disease takes less than around 5 years to develop. Inversely, the mean age for FIV-infection was 4.9 years old, and only $7.9 \%$ cats were less than 1 year old, which agrees with previous results [8]. FIV-infected cats may survive several years, as supported by the presence of $31.6 \%$ of cats $\geq 7$ years old. In addition, the disease may take longer to develop after infection, as in general terms, in FIV-infection the disease became more severe with increasing age $(75.0 \%$ of the FIV-infected cats $>7$ years old showed clinical signs). The age distribution of $\mathrm{FF}^{+}$cats was intermediate between $\mathrm{FIV}^{+}$and $\mathrm{FeLV}^{+}$animals.

The blood cell counts values were seen to be frequently altered in both retroviral infections, and no clear differ- ences were observed between $\mathrm{FIV}^{+}$and $\mathrm{FeLV}^{+}$cats. Anemia was seen in $32.3 \%$ of the $\mathrm{FeLV}^{+}$cats and in $31.6 \%$ of the $\mathrm{FIV}^{+}$cats, which agrees with previous reports $[2,6,14,16-19] . \mathrm{FeLV}^{+}$cats with clinical signs had a higher tendency to have subnormal RBC counts than those without signs. Contrariwise to FeLV-infection, a similar percentage of $\mathrm{FIV}^{+}$cats with and without clinical signs developed anemia, suggesting that in FIV-infection anemia derives as a direct effect of the virus [19], even though the presence of secondary infections or stress may increase its severity or favor its appearance.

As reported previously $[11,17,19]$, the alterations in the lymphocytes and neutrophils were more frequent than any of the other white blood cell populations. Most cats had cytopenia rather than cytophilia, which seems to indicate that both FeLV and FIV impede new white cells from being formed or favor their destruction. Neutropenia was the most frequent alteration of the leukogram, which agrees with reports from other authors $[6,17,18,20]$, and it was seen to be unrelated to the clinical status of the animal, since some animals had this abnormality in the absence of clinical signs, while others had normal neutrophil counts but a high clinical score. Also, unlike previous reports [6], neutropenia was not more frequent in $\mathrm{FIV}^{+}$cats than in $\mathrm{FeLV}^{+}$ones, and the lowest percentage of this abnormality corresponded to $\mathrm{FF}^{+}$cats.

Though the percentage of lymphopenia and neutropenia were similar in both infections, $\mathrm{FeLV}^{+}$cats had a higher tendency to have both cellular populations altered than $\mathrm{FIV}^{+}$cats $\left(40.0 \%\right.$ and $18.2 \%$ for $\mathrm{FeLV}^{+}$and $\mathrm{FIV}^{+}$cats with abnormal WBC counts, respectively). This difference could reside in the type of cells infected by each of the retroviruses. FeLV invades the bone marrow, and may affect hematopoietic stem cells resulting in decreased blood counts of different cellular populations. On the other hand, FIV infects mature cells, which would normally belong to a single type. $\mathrm{FF}^{+}$cats were more similar to $\mathrm{FIV}^{+}$animals than to FeLV-infected ones, since the percentage of cats in which both neutrophil and lymphocyte counts were affected was low (20.0\%).

As expected, significantly higher percentage of $\mathrm{FIV}^{+}$ than $\mathrm{FeLV}^{+}$cats had a decreased $\mathrm{CD}^{+}: \mathrm{CD}^{+}$ratio $(\mathrm{p}<$ $0.01)$. The mean $\mathrm{CD}^{+}: \mathrm{CD}^{+}$ratio of $\mathrm{FIV}^{+}$cats was similar to data published by Hohdatsu et al. [21], but lower than other reports [22]. A high number of $\mathrm{FF}^{+}$cats also had a subnormal $\mathrm{CD}^{+}: \mathrm{CD}^{+}$ratio. Both $\mathrm{FeLV}^{+}$and $\mathrm{FIV}^{+}$cats with clinical signs had a higher probability of presenting a lower $\mathrm{CD} 4^{+}: \mathrm{CD} 8^{+}$ratio than those without signs, suggesting that both viruses may induce alterations of the cellular immune response; however, most $\mathrm{FeLV}^{+}$ cats had $\mathrm{CD}^{+}: \mathrm{CD}^{+}$ratios within the normal ranges.

FIV p24CA or RT could not be detected in any of the cats included in the study, corroborating the low concentration of the viral particles in the plasma of infected cats. 
This contrasts with previous results in which it was found that neutropenia in $\mathrm{FIV}^{+}$cats was associated with plasma viremia, similarly to late $\mathrm{HIV}$-infection [17]. Another explanation for the lack of p24CA detection could be the low sensitivity of the test used. On the other hand, the plasma of all $\mathrm{FeLV}^{+}$cats included in the study was positive to $\mathrm{p} 27 \mathrm{CA}$, but RT was detected in only $71.0 \%$ of these cats. p27CA is synthesized in excess and is not always associated with infective viral particles [23], which would be those with RT activity [24]. Statistically significant different percentages of animals in which RT was detected were found in each $\mathrm{CG}(\mathrm{p}<0.05)$, being the lowest for CG1 and the highest for CG3. This seems to indicate an association between the presence of circulating infective virions and the increase in clinical score.

In conclusion, the clinical status did not unequivocally correspond to the hematological parameters in retroviral-infected cats, but rather to the virological status, especially in $\mathrm{FeLV}^{+}$cats. FeLV induces a more severe syndrome than FIV, affecting more blood cell types and provoking death of affected animals at a much earlier age than FIV. Double-infected cats did not have a more severe disease than mono-infected animals, and their results were, in general, closer to those of $\mathrm{FIV}^{+}$than to those of FeLV cats; however, larger studies with $\mathrm{FF}^{+}$cats are necessary to better understand the pathogenesis in double infections.

\section{Acknowledgements}

This study was supported by public funding (AGL200505248/GAN, UCM 920620-2008). VMC is a grantee of the Ministry of Science. The technical assistance of Ana Angulo in the processing of the samples and the editorial assistance of David A. Bruhn are greatly acknowledged. We thank all the practitioners involved in this study for their valuable collaboration, and Dr. Nelida Gomez for her constructive comments and help in establishing the clinical scoring.

\section{REFERENCES}

[1] C. E. Goldkamp, J. K. Levy, C. H. Edinboro and J. L. Lactara, "Seroprevalences of Feline Leukemia Virus and Feline Immunodeficiency Virus in Cats with Abscesses or Bite Wounds and Rate of Veterinarian Compliance with Current Guidelines for Retrovirus Testing," Journal of the American Veterinary Medical Association, Vol. 232, No. 8, 2008, pp. 1152-1158. doi:10.2460/javma.232.8.1152

[2] S. P. Dunham and E. Graham, "Retroviral Infections of Small Animals," Veterinary Clinics of North America: Small Animal Practice, Vol. 38, No. 4, 2008, pp. 879-901. doi:10.1016/j.cvsm.2008.03.005

[3] M. Bendinelli, M. Pistello, S. Lombardi, S. Lombardi, A. Poli, C. Garzelli, D. Matteucci, et al., "Feline ImmunodeFiciency Virus: An Interesting Model for AIDS Studies and an Important Cat Pathogen," Clinical Microbiology Reviews, Vol. 8, No. 1, 1995, pp. 87-112.

[4] M. J. Hosie, D. Addie, S. Belák, C. Boucraut-Baralon, H. Egberink, T. Frymus, et al., "Feline Immunodeficiency. ABCD Guidelines on Prevention and Management," Journal of Feline Medicine and Surgery, Vol. 11, No. 7, 2009, pp. 575-584. doi:10.1016/j.jfms.2009.05.006

[5] A. Arjona, N. Barquero, A. Doménech, G. Tejerizo, V. M. Collado, C. Toural, et al., "Evaluation of a Novel Nested PCR for the Routine Diagnosis of Feline Leukemia Virus (FeLV) and Feline Immunodeficiency Virus (FIV)," Journal of Feline Medicine and Surgery, Vol. 9, No. 1, 2007, pp. 14-22. doi:10.1016/j.jfms.2006.05.009

[6] S. Gleich and K. Hartmann, "Hematology and Serum Biochemistry of Feline Immunodeficiency Virus-Infected and Feline Leukemia Virus-Infected Cats," Journal of Veterinary Internal Medicine, Vol. 23, No. 3, 2009, pp. 552-558. doi:10.1111/j.1939-1676.2009.0303.x

[7] H. Lutz, D. Addie, S. Belák, C. Boucraut-Baralon, H. Egberink, T. Frymus, et al., "Feline Leukaemia. ABCD Guidelines on Prevention and Management," Journal of Feline Medicine and Surgery, Vol. 11, No. 7, 2009, pp. 565-574. doi:10.1016/j.jfms.2009.05.005

[8] A. Arjona, E. Escolar, I. Soto, N. Barquero, D. Martin and E. Gomez-Lucia, "Seroepidemiological Survey of Infection by Feline Leukemia Virus and Immunodeficiency Virus in Madrid and Correlation with Some Clinical Aspects," Journal of Clinical Microbiology, Vol. 38, No. 9, 2000, pp. 3448-3449.

[9] E. Natoli, L. Say, S. Cafazzo, R. Bonanni, M. Schmid and D. Pontier, "Bold Attitude Makes Male Urban Feral Domestic Cats more Vulnerable to Feline Immunodeficiency Virus," Neuroscience \& Biobehavioral Reviews, Vol. 29, No. 1, 2005, pp. 151-157. doi:10.1016/j.neubiorev.2004.06.011

[10] E. E. Sparger, A. M. Beebe, N. Dua, S. Himathongkam, J. H. Elder, M. Torten, et al., "Infection of Cats with Molecularly Cloned and Biological Isolates of the Feline Immunodeficiency Virus," Virology, Vol. 205, No. 2, 1994, pp. 546-553. doi:10.1006/viro.1994.1677

[11] K. Hartmann, "Antiviral and Immunodulatory ChemoTherapy,” In: C. E. Greene, Ed., Infectious Diseases of the Dog and Cat, Saunders Elsevier, St. Louis, 2006, pp. 1025.

[12] N. C. Pedersen, M. Torten, B. Rideout, E. Sparger, T. Tonachini, P. A. Luciw, et al., "Feline Leukemia Virus Infection as a Potentiating Cofactor for the Primary and Secondary Stages of Experimentally Induced Feline Immunodeficiency Virus Infection," Journal of Virology, Vol. 64, No. 2, 1990, pp. 598-606.

[13] E. A. Hoover, R. G. Olsen, W. D. Hardy Jr., J. P. Schaller and L. E. Mathes, "Feline Leukemia Virus Infection: Age-Related Variation in Response of Cats to Experimental Infection," Journal of the National Cancer Institute, Vol. 57, No. 2, 1976, pp. 365-369.

[14] R. Hofmann-Lehmann, E. Holznagel, P. Ossent and H. Lutz, "Parameters of Disease Progression in Long-Term Experimental Feline Retrovirus (Feline Immunodeficiency Virus and Feline Leukemia Virus) Infections: Hematology, 
Clinical Chemistry, and Lymphocyte Subsets," Clinical and Vaccine Immunology, Vol. 4, No. 1, 1997, pp. 33-42.

[15] S. E. Gleich, S. Krieger and K. Hartmann, "Prevalence of Feline Immunodeficiency Virus and Feline Leukaemia Virus among Client-Owned Cats and Risk Factors for Infection in Germany," Journal of Feline Medicine and Surgery, Vol. 11, No. 12, 2009, pp. 985-992. doi:10.1016/j.jfms.2009.05.019

[16] E. J. Fleming, D. L. McCaw, J. A. Smith, G. M. Buening and C. Johnson, "Clinical, Hematologic, and Survival Data from Cats Infected with Feline Immunodeficiency Virus: 42 Cases (1983-1988)," Journal of the American Veterinary Medical Association, Vol. 199, No. 7, 1991, pp. 913-916.

[17] G. H. Shelton and M. L. Linenberger, "Hematologic Abnormalities Associated with Retroviral Infections in the Cat," Seminars in Veterinary Medicine \& Surgery (Small Animal), Vol. 10, No. 4, 1995, pp. 220-233.

[18] K. de Mari, L. Maynard, A. Sanquer, B. Lebreux and H. M. Eun, "Therapeutic Effects of Recombinant Feline Interferon-Omega on Feline Leukemia Virus (FeLV)-Infected and FeLV/Feline Immunodeficiency Virus (FIV)-Coinfected Symptomatic Cats," Journal of Veterinary Internal Medicine, Vol. 18, No. 4, 2004, pp. 477-482.

[19] R. K. Sellon and K. Hartmann, "Feline Immunodeficiency Virus Infection," In: C. E. Greene, Ed., Infectious Diseases of the Dog and Cat, Saunders Elsevier, St. Louis, 2006, pp.
131-142.

[20] K. Hartmann, "Feline Immunodeficiency Virus Infection: An Overview," The Veterinary Journal, Vol. 155, No. 2, 1998, pp. 123-137.

[21] T. Hohdatsu, A. Yamazaki, M. Yamada, H. Kusuhara, T. Kaneshima and H. Koyama, "Ability of CD8(+) T Cell Anti-Feline Immunodeficiency Virus Activity Correlated With Peripheral CD4(+) T Cell Counts and Plasma Viremia," Microbiology and Immunology, Vol. 47, No. 10, 2003, pp. 765-773.

[22] A. Walker, P. J. Canfield and D. N. Love, "Analysis of Leucocytes and Lymphocyte Subsets for Different Clinical Stages of Naturally Acquired Feline Immunodeficiency Virus Infection," Veterinary Immunology and Immunopathology, Vol. 44, No. 1, 1994, pp. 1-12. doi:10.1016/0165-2427(94)90165-1

[23] A. J. Marozsan, E. Fraundorf, A. Abraha, H. Baird, D. Moore, R. Troyer, I. Nankja, et al., "Relationships between Infectious Titer, Capsid Protein Levels, and Reverse Transcriptase Activities of Diverse Human Immunodeficiency Virus Type 1 Isolates," Journal of Virology, Vol. 78, No. 20, 2004, pp. 11130-11141. doi:10.1128/JVI.78.20.11130-11141.2004

[24] G. L. Niermann and G. C. Buehring, "Hormone Regulation of Bovine Leukemia Virus via the Long Terminal Repeat," Virology, Vol. 239, No. 2, 1997, pp. 249-258. doi:10.1006/viro.1997.8868 